\title{
Rapid bacterial identification based on surface-enhanced Raman scattering and machine learning (Conference Presentation) (Withdrawal Notice)
}

Chi-Sing Ho, Neal Jean, Amr Saleh, Stefano Ermon, Niaz Banaei, et al.

Chi-Sing Ho, Neal Jean, Amr Saleh, Stefano Ermon, Niaz Banaei, Jennifer A. Dionne, "Rapid bacterial identification based on surface-enhanced Raman scattering and machine learning (Conference Presentation) (Withdrawal Notice)," Proc. SPIE 10479, Light-Based Diagnosis and Treatment of Infectious Diseases, 1047904 (10 April 2018); doi: 10.1117/12.2291601

SPIE. Event: SPIE BiOS, 2018, San Francisco, California, United States 


\section{Rapid bacterial identification based on surface-enhanced Raman scattering and machine learning (Conference Presentation) (Withdrawal Notice)}

Proc. SPIE 10479, 1047904 (2018)

Online Publication Date: 14 March 2018

Withdrawn from Publication: 10 April 2018

Conference Date: 29-31 January 2018

Conference Location: San Francisco, California, United States

Conference Title: Light-Based Diagnosis and Treatment of Infectious Diseases

Conference Chairs: Tianhong Dai

Chi-Sing Ho Neal Jean, Amr Saleh Stefano Ermon, Niaz Banaei Jennifer A Dionne, Stanford Univ. (United States)

Publisher's Note: This conference presentation, originally published on 14 March 2018, was withdrawn

per author request. 